\title{
Endoscope-Assisted Parapharyngeal Space Abscess Drainage
}

\author{
Dong Sik Chang ${ }^{1}$, Jun Lee ${ }^{1}$, So Young Choi ${ }^{2}$, and Myoung Su Choi ${ }^{1}$ \\ ${ }^{1}$ Departments of Otolaryngology-Head and Neck Surgery, ${ }^{2}$ Radiology, Eulji University Medical Center, \\ Eulji University School of Medicine, Daejeon, Korea
}

\section{내시경을 이용한 부인두 농양의 경구강 배농술}

장동식 ${ }^{1} \cdot$ 이 준 ${ }^{1} \cdot$ 최소영 $^{2} \cdot$ 최명수 $^{1}$

을지대학교 의과대학 이비인후과학교실, ${ }^{1}$ 영상의학교실 ${ }^{2}$

\author{
Received April 15, 2019 \\ Revised August 26, 2019 \\ Accepted September 16, 2019 \\ Address for correspondence \\ Myoung Su Choi, MD \\ Department of Otolaryngology- \\ Head and Neck Surgery, \\ Eulji University Medical Center, \\ Eulji University School of Medicine, \\ 95 Dunsanseo-ro, Seo-gu, \\ Daejeon 35233, Korea \\ Tel +82-42-611-3129 \\ Fax $+82-42-611-3136$ \\ E-mail mschoi@eulji.ac.kr
}

Background and Objectives Parapharyngeal space abscess (PPSA) may cause severe complications such as, airway obstruction, jugular thrombophlebitis, and mediastinitis unless early diagnosed and properly treated. Transoral drainage is known to reduce morbidity and hospital stays compared to the external drainage. The aim of this study is to assess the effect of endoscope when draining of PPSA via transoral approach.

Subjects and Method We retrospectively reviewed charts of patients who were diagnosed with PPSA and treated surgically between February 2013 and September 2018. We included in the study 39 patients who underwent incisional drainage via transoral approach. Pateints were excluded had they undergo drainage via external approach or who treated with medication alone or operated for parapharyngeal space tumor. Thirty-nine patients were classified into two groups according to whether an endoscope was used or not when draining PPSA. We compared the hospital stays, estimated blood loss (EBL), operating time, revision rate, depth of abscess, and postoperative complications between two groups.

Results Of the 39 patients [22 males (M), 17 females $(\mathrm{F})$ ], 13 patients (M:F=7:6) were classified as an endoscope group (EG) and $26(\mathrm{M}: \mathrm{F}=15: 9)$ as without endoscope group (WEG). The mean hospital stays of the EG and WEG were 7.6 \pm 4.6 and $9.8 \pm 4.8$ days, respectively $(p=0.188)$; the mean EBL of the EG and WEG were 222.2 and $254.0 \mathrm{~mL}$, respectively ( $p=0.595)$; the mean operating time of the EG and WEG were $40.0 \pm 22.5$ and $35.4 \pm 14.5$ minutes, respectively ( $p=$ 0.457 ); the mean depth of PPSA of the EG and WEG were $4.5 \pm 0.9$ and $4.0 \pm 0.7 \mathrm{c}$-spine level, respectively ( $p=0.043$ ), and the revision cases of the EG and WEG were 1 and 2 , respectively $(p=1.000)$.

Conclusion Endoscopes enabled the draining of PPSA to sit more deeply in the neck compared without it. Korean J Otorhinolaryngol-Head Neck Surg 2020;63(7):314-8

\section{서 론}

항생제가 널리 보급된 최근에도 심경부 감염의 비율은 과

This is an Open Access article distributed under the terms of the Creative Commons Attribution Non-Commercial License (https://creativecommons.org/licenses/by-nc/4.0) which permits unrestricted non-commercial use, distribution, and reproduction in any medium, provided the original work is properly cited.
거에 비해 크게 감소하고 있지 않다. ${ }^{1,2)}$ 부인두 농양은 편도 주 위 농양에 이어 두 번째로 흔한 심경부 감염이다. ${ }^{3,4)}$ 부인두 공 간은 해부학적으로 인두 점막에 인접하여, 호흡기 경로를 통 한 인두염이나 편도선염 또는 치성 감염에 의해 주로 발생한 다. ${ }^{3-5)}$ 부인두 공간은 심경부의 모든 중요한 근막 공간들과 교 통하는 중심이므로 이 공간이 감염되면 다른 주위 공간들로 
염증이 쉽게 파급될 수 있다. 따라서, 부인두 공간에 생긴 농 양은 조기에 적절히 치료하지 않으면 기도폐색, 경정맥염, 종 격동염 등 치명적인 합병증을 유발할 수 있다.,6,7)

부인두 농양 치료에 있어서 외과적 절개배농은 항생제 치 료와 더불어 조기에 염증을 조절할 수 있는 핵심 치료이다. 절개배농술은 경부접근법과 구강접근 방식이 있는데, 경부접 근법에 비해 구강접근 방식은 흥터를 남기지 않고, 치료 기간 을 줄이고, 합병증을 줄일 수 있는 장점이 있다.,1,3) 최근에는 내시경이 의료의 여러 분야에 도입되어 나안으로는 접근이 어려웠던 부분도 고화질과 확대 시야를 통해 가능해지고 있 다. 본 연구에서는 부인두 농양을 구강을 통해 배농 시 내시 경을 사용하였을 때와 사용하지 않은 경우를 비교하여 어떠 한 치료 결과가 있는지 알아보고자 하였다.

\section{대상 및 방법}

본원에서 2013년 2월 2018년 9월까지 부인두 농양으로 진 단받아 수술적 치료를 했던 환자를 대상으로, 의무기록을 후 향적으로 검토하였다. 수술자는 2 명의 의사에 의해 시행되었 다(Chang DS, Choi MS). 이 연구는 병원의 IRB의 심의를 받 아 진행되었다(EMC-2018-10-003).

연구에 선정된 기준으로는 부인두 공간에 생긴 농양으로 진단되어 구강으로만 절개배농을 시행한 경우만 포함시켰다. 부인두 공간은 후두 주위 공간과 인두 점막 공간을 포함하였 으며, 약물 치료만으로 호전된 환자나, 경부접근을 통한 절개 배농을 시행한 경우, 부인두 공간에 발생한 종양으로 수술한 경우, 수술 후 3 개월 이상 경과 관찰을 할 수 없었던 자는 제 외하였다.

이학적 검사와 경부 $\mathrm{CT}$ 로 부인두 농양을 진단하면 광범위 항생제를 조합하여 정맥주사하였고 48 72시간의 보존적 치 료에도 임상 증상의 호전이 없거나 악화된 경우는 세침흡인 이나 절개배농을 시행하였으며, 기도폐색이 임박하였거나 동 반된 경우는 광범위 항생제 치료를 시작함과 더불어 바로 기 도확보와 절개배농을 시행하였다. 임상 증상 호전 여부의 판 단은 인후통, 연하통, 연하곤란, 경부 동통 같은 환자의 증상 과 이학적 검사상 종창이 호전되고 경부 압통이 호전된 경우 로 판단하였고, 임상 증상이 호전되었다고 판단한 경우는 보 존적 치료를 연장하였다. 절개배농이나 세침흡인을 시행한 경우는 세균동정 결과에 따라 감수성에 맞은 항생제로 바꾸 어 치료하였다.

\section{내시경 사용 여부에 따른 수술 방식}

고식적인 부인두 농양의 구강을 통한 절개배농은, 구강을
견인기로 벌려 측인두를 노출시키고, 진단 시 시행한 경부 CT 를 보고 파악한 농양을 덮고 있다고 의심되는 측인두 점막을 통해 18 게이지 바늘을 흡인하여 고름의 존재를 확인한 후, 수직으로 절개하여 배농한다. 내시경을 이용한 경우에도, 동 일하게 구강을 견인기로 벌려 측인두를 노출시키고, 농양을 덮고 있다고 의심되는 부위를 내시경을 보면서 바늘흡인을 시 행한다. 바늘흡인상 고름을 확인하면 동일하게 수직으로 절 개하여 배농한다. 바늘흡인상 고름을 확인하지 못하였지만, $\mathrm{CT}$ 상 농양이 명확하며, 측인두나 후두 인접 점막하에 농양이 위치한 경우는 고주파수 기구인 Coblator Evac(Arthrocare ENT, Sunnyvale, CA, USA)을 이용하여 주변 인두 점막과 점막하 조직을 넓게 절제하여, 농양을 덮고 있는 조직을 얇게 하면서 농양을 찾아나갔다(Fig. 1). 출혈이 있는 경우는 $\mathrm{Co}^{-}$ blator를 이용하여 지혈시켰으며, 가능하면 배액관을 삽입하 였고, 배액관을 삽입하기 어려운 부위는 절개 부위 점막을 넓 게 제거하여 넓혔다(Fig. 1).

내시경을 이용한 그룹과 이용하지 않은 그룹 간에 나이, 성 별, C-reactive protein(CRP), 입원 기간, 추정 출혈량, 재수술 빈도, 기관절개술 빈도, 농양의 깊이 등을 비교 분석하였다.

\section{추정 출혈량 계산 ${ }^{8}$}

추정 출혈량은 다음과 같은 식으로 계산하였다. 수술 전 혈 색소와 수술 후 24 시간 이내에 시행한 혈액검사의 혈색소를 구한 후, 환자의 키와 몸무게를 측정하였다[estimated blood loss=추정 초기 혈액양(estimated blood volume, EBV) $\times($ 초 기 혈색소-후기 혈색소)/(후기 혈색소)].

추정 초기 혈액양 $(\mathrm{EBV})$ 은, 남성은: $\mathrm{EBV}(\mathrm{mL})=0.0003669$ $\times$ 키 ${ }^{3}(\mathrm{~cm})+[32.19 \times$ 체중 $(\mathrm{kg})+604]$, 여성은: $\mathrm{EBV}(\mathrm{mL})=$
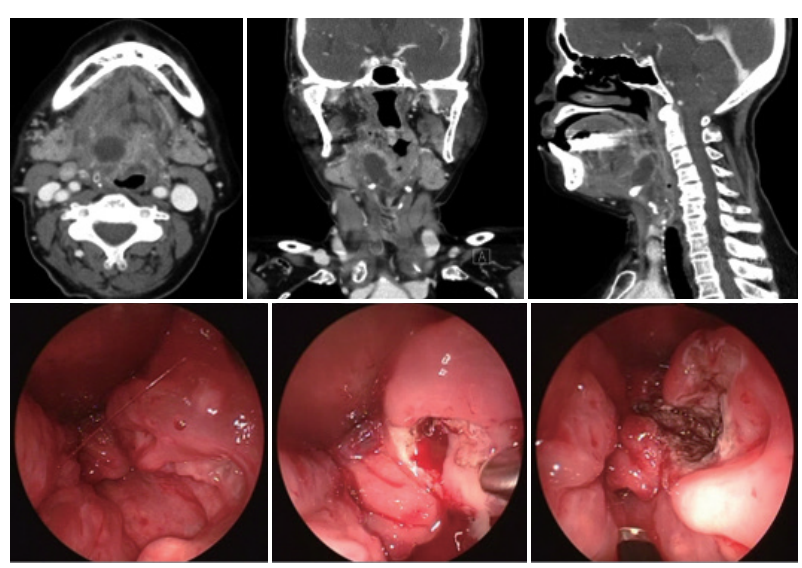

Fig. 1. Enhanced CT scan revealed an ovoid abscess pocket involving the right parapharyngeal and paralaryngeal space, causing significant airway narrowing (upper). Incision and drainage of the abscess was performed with Evac Coblator (Arthrocare ENT) and endoscope via transoral approach (lower). 
$0.0003561 \times$ 키 $\left.\right|^{3}(\mathrm{~cm})+[33.08 \times$ 체중 $(\mathrm{kg})+183]$.

배농한 농양의 깊이 측정

배농한 농양의 깊이를 $\mathrm{CT}$ 의 시상면에서 측정하였다. 시상 면 CT에서 농양의 하연에 수평으로 선을 그어서, 이에 해당 하는 경추 위치로 정하였다(Fig. 2).

\section{통계 분석}

SPSS 18.0(SPSS, Inc., Chicago, IL, USA)을 이용하여 통 계적 검증을 시행하였고, 내시경을 이용한 그룹에 포함된 환 자가 13명이어서 정규성 검토를 Kolomogorov-Smirnov test, Shapiro-Wilk test를 이용하여 검토하였고, $p$ 값이 0.05 이상 인 경우는 t-test, 0.05 미만인 경우는 비모수 검정을 시행하 였다. 두 그룹 간 비교는 t-test, Mann-Whitney U test를 시 행하였고, 두 그룹의 기술적 통계량을 먼저 시행하였으며, 그 룹 간 비교는 t-test를 이용해서, chi-square test나, Fisher's exact test를 이용하여 분석하였다.

\section{결 과}

2013년 2월 2018년 9월까지 부인두 농양으로 본원에 입 원 치료했던 61명의 환자 중에서 약물치료만으로 호전되었던 12 명, 경부접근을 통해 절개배농을 한 10 명을 제외하고, 구 강접근법을 통한 수술적 절개배농을 시행하였던 39 명의 환자 가 연구에 포함되었다. 내시경 그룹은 13 명으로, 평균나이는

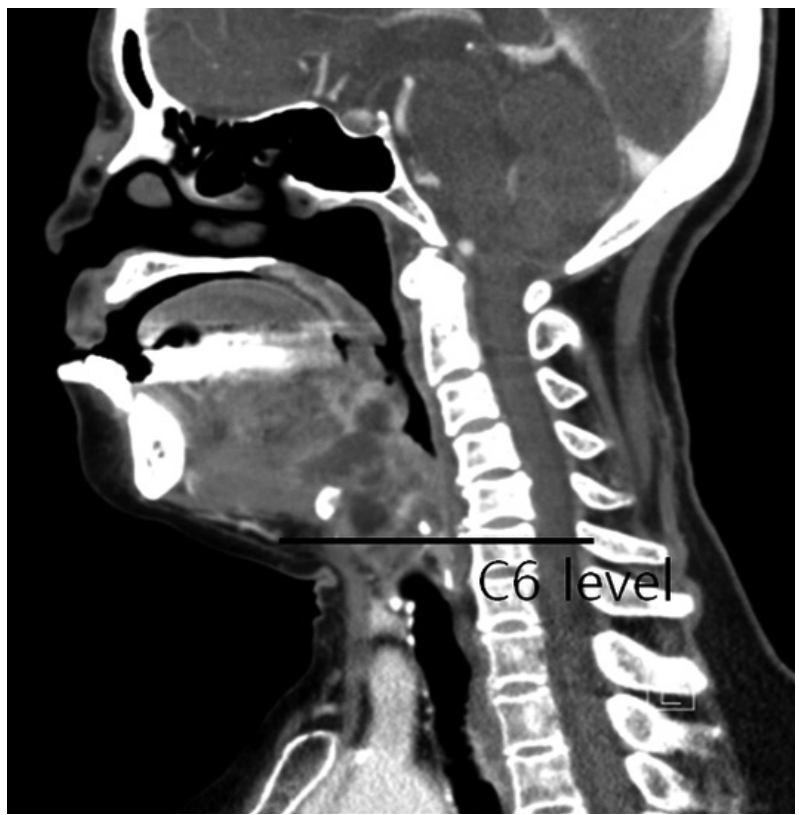

Fig. 2. Measuring depth of the abscess at which the horizontal line of the lower margin of it meets the cervical vertebrae in CT.
60.3세, 남녀비는 7:6이었다. 내시경을 이용하지 않은 그룹(고 식적 절개 그룹)은 26명으로, 평균나이는 54.7세, 남녀비는 15:9였다(Table 1). 내시경 그룹에서 초기 CRP는 $8.9 \mathrm{mg} / \mathrm{L}$, 고식적 절개 그룹에서는 $9.8 \mathrm{mg} / \mathrm{L}$ 로 나왔다. 기도폐색으로 기관절개술을 시행한 경우는 내시경 그룹에서는 5명, 고식적 절개 그룹에서는 14 명으로 유의한 차이는 없었다. 당뇨병이 있는 경우가 내시경 그룹에서는 3명, 고식적 절개 그룹에서는 6명으로 두 그룹 간 차이는 없었다. 내시경 그룹에서, 절개 배 농 전후의 혈색소는 수술 전 39.9, 수술 후는 38.8이며, 고식 적 절개 그룹에서 수술 전 혈색소는 41.5, 수술 후는 39.0으로 나왔다. 추정 출혈량은 내시경 그룹은 $222.2 \mathrm{~mL}$ 로, 고식적 절개 그룹의 $254.0 \mathrm{~mL}$ 보다 낮게 나왔으나 통계적으로 유의하 지는 않았다(Table 2). 내시경 그룹은 13명 중 12명에서 고름 을 확인할 수 있었으며(92\%), 고식적 절개 그룹은 26명 중 21 명에서 $(81 \%)$ 에서 고름을 확인할 수 있었다. 수술 시간은 내시 경 그룹이 평균 40 분으로 고식적 절개 그룹 35.4 분보다 길게

Table 1. Clinical characteristics of patients

\begin{tabular}{lccc}
\hline & $\begin{array}{c}\text { With } \\
\text { endoscope }\end{array}$ & $\begin{array}{c}\text { Without } \\
\text { endoscope }\end{array}$ & p-value \\
\hline Patients & 13 & 26 & \\
Age (years) & $60.3 \pm 3.8$ & $54.7 \pm 3.1$ & $0.274^{*}$ \\
Male/female & $7 / 6$ & $15 / 9$ & $0.609^{\ddagger}$ \\
Diabetes & 3 & 6 & $1.000^{\dagger}$ \\
Anticoagulation & 3 & 2 & $0.321^{\dagger}$ \\
CRP (mg/L) & 8.9 & 9.8 & $0.675^{*}$ \\
Tracheostomy & 5 & 14 & $0.313^{\dagger}$ \\
RPSA & 2 & 1 & $0.276^{\dagger}$ \\
PTA & 5 & 13 & $0.386^{\ddagger}$ \\
Revision & 1 & 2 & $1.000^{\dagger}$ \\
Weight (kg) & $65.5 \pm 9.1$ & $66.2 \pm 11.7$ & $0.846^{*}$ \\
Height (cm) & $165.7 \pm 10$ & $166.1 \pm 8.3$ & $0.910^{*}$ \\
Hct (i) & $39.9 \pm 5.1$ & $41.5 \pm 3.3$ & 0.257 \\
Hct (f) & $38.8 \pm 4.3$ & $39.0 \pm 2.9$ & 0.876 \\
\hline
\end{tabular}

*t-test, †Fischer's exact test, ‡chi-square test. RPSA: retropharyngeal space abscess, PTA: peritonsillar abscess, Hct (i): initial hematocrit, Hct (f): final hematocrit

Table 2. Comparison of treatment outcome between two groups

\begin{tabular}{lccc}
\hline & $\begin{array}{c}\text { With } \\
\text { endoscope }\end{array}$ & $\begin{array}{c}\text { Without } \\
\text { endoscope }\end{array}$ & p-value \\
\hline Presence of pus & 12 & 21 & $0.643^{\dagger}$ \\
EBL (mL) & 222.2 & 254.0 & $0.595^{*}$ \\
Op. time (min) & $40.0 \pm 22.5$ & $35.4 \pm 14.5$ & $0.457^{*}$ \\
Hosp. stay (days) & $7.6 \pm 4.6$ & $9.8 \pm 4.8$ & $0.188^{*}$ \\
Abscess depth & $4.5 \pm 0.9$ & $4.0 \pm 0.7$ & $0.043^{*}$ \\
(c-spine level) & & &
\end{tabular}

*t-test, tFischer's exact test. EBL: estimated blood loss, Op: operating, Hosp: hospital, c-spine: cervical spine 
나왔으나, 통계적으로 유의하지는 않았다(Table 2). 입원 기간 은 내시경 그룹이 평균 7.6일로, 고식적 절개 그룹 9.8일보다 짧게 나왔으나 통계적으로 유의하지는 않았다. 농양이 남아 있어 추가 배농술을 시행한 경우는 내시경 그룹에서는 1명이 며, 고식적 절개 그룹에서는 2명으로, 두 그룹 간 차이를 보이 지 않았다. 배액술을 시행한 농양의 깊이는 내시경 그룹에서 평균 4.5경추 레벨, 고식적 절개 그룹에서는 4경추 레벨로 나 와, 내시경 그룹에서 통계적으로 유의하게 더 깊은 곳에 위치 한 농양을 배액한 것으로 나왔다( $p=0.043$ )(Table 2). 두 그룹 모두에서 수술 후 합병증은 없었다.

\section{고 찰}

부인두 농양이 생기는 주요한 원인으로는 인후염이나 편도 선염, 그리고 치성 감염이며, ${ }^{3,4,910)}$ 기타 원인으로 침샘 감염, 유양돌기염, 화농성 림프절염으로 알려져 있다. ${ }^{34)}$ 편도 주위 농양은 가장 흔한 심경부 감염이자, 부인두 농양의 가장 흔한 원인이 되기도 한다. ${ }^{34,9)}$ Kawabata 등 ${ }^{11)}$ 은 99 명의 편도 주위 농양 환자를 분석하여 13명(13\%)에서 편도 주위 밖 부인두 공간이나 후인두 공간으로 파급된 것을 CT상 확인하였고, 편 도 주위 농양이 위쪽에서 발생한 경우는 3명, 아래쪽에서 농 양이 발생한 경우는 10 명으로, 아래쪽에서 발생한 편도 주위 농양이 위쪽에서 발생한 경우보다 부인두나 후인두농양을 흔 하게 발생시킨다고 보고하였다. Licameli와 Grillone ${ }^{12)}$ 은 편 도 주위 공간 아래쪽 측벽 $1 / 3$ 이 위쪽 $2 / 3$ 에 비해 해부학적으 로 약하다고 보고하였다. Klug 등 ${ }^{9}$ 의 연구에서는 부인두 농 양 환자의 $52 \%$ 에서 편도 주위 농양이 같이 발생한 것으로 보 고하여, 편도 감염이 부인두 농양의 주요한 원인임을 지적하 였다. 우리 연구에서도 39 명의 부인두 농양 환자 중에서 편도 주위 농양이 같이 발생한 경우는 18 명(46\%)으로, 위의 연구 와 비슷한 결과를 보였다(Table 1). 부인두 농양의 주요한 원 인이 편도 주위 농양이기 때문에, 치료로서 부인두 농양 배농 과 더불어 동시에 편도절제술이 많은 지지를 받고 있다.9,11 편 도절제술을 동시에 시행하면 편도와(tonsil bed)와 연결된 부 인두 농양을 완전히 개방할 수 있어, 배농 성공률과 입원 기 간을 단축할 수 있다고 알려져 있다. ${ }^{4)}$ 하지만, 부인두 농양 치 료에서 즉각적인 편도절제술은 출혈의 우려와, 감염의 확산 등으로 여전히 많은 이비인후과 의사들이 꺼려하는 술기이다. 또한, 우리나라에서는 편도선 절제술이 포괄수가제에 포함되 어 있어서, 부인두 농양 배농 시 동시에 편도선 절제술은 시 행하기 어려운 실정이다.

부인두 농양의 두 번째로 흔한 원인인 치성 감염은 먼저 저 작 공간이나 구강저 공간을 감염 후, 부인두 공간이나 악하
공간으로 파급되는 경우가 많아, 부인두 공간을 침범한 경우 는 이미 다른 공간을 침범한 경우가 드물지 않기 때문에, 경 부를 통한 절개배농을 하거나, 구강을 통한 절개배농과 같이 하는 경우가 많다. $\mathrm{Hah}$ 등 $^{13)}$ 은 소아 126 명의 심경부 감염 환 자를 분석해서 이 중 13 명의 경부를 통해 절개배농을 시행한 그룹의 위험 인자를 분석하였는데, 악하 공간을 침범한 경우 가 유의한 위험 인자임을 보고하였다. 최근에는 선택된 사례 에서 치성으로 발생한 농양을 초음파나 투시를 이용하여 최 소 침습적으로 경피배액을 시행한 사례를 보고하였다. ${ }^{14-16)}$ Yusa 등드는 악하 공간, 설하 공간, 협부 공간에 발생한 8명의 치성 경부 농양 환자를 초음파와 도플러를 이용하여 혈관 손 상 없이 성공적으로 배농하였다고 보고하였다. 과거에는 경 동맥의 바깥쪽에 위치한 농양은 경부를 통한 절개배농이 표 준이었으나, 최근에는 초음파나 투시를 이용한 경피배액술이 점차 대신하고 있는 추세이다.

소아 심경부 농양에 있어서 항생제 주사 치료와 스테로이드 병합 요법으로 수술적 절개배농 없이 호전된 연구가 보고되었 다. ${ }^{17,18)}$ 그러나, 이 경우에도 CT의 추적 조사가 필요하여 방사 선 노출량이 증가할 수 있고, 약물이 효과를 발휘하기까지 절 개배농에 비해 입원 기간이 길어질 수 있다는 단점이 있다. ${ }^{17,18)}$

부인두 농양의 경구를 통한 절개배농은 입원 기간이 짧고, 흉터를 남기지 않고, 합병증도 경부를 통한 접근에 비해서 줄 일 수 있는 장점이 있다.,1,3) 다만, 경동맥의 내측에 생긴 부인 두 농양에 한해서만 시도되고 있으며, 먼저 바늘흡인으로 고 름의 여부를 확인해야만 절개를 시행할 수 있는 단점이 있다. 바늘흡인의 정확도를 높이기 위해서 초음파를 이용하여 바 늘이 농양집에 제대로 위치해 있는지 확인하는 방법을 시도 하기도 하였다. ${ }^{15,16}$ Cable 등 ${ }^{19)}$ 은 12 명의 부인두 농양 소아 환 자에서 무탐침 정위기법을 이용한 경구강 절개배농술을 보고 하였다.

본 연구에서 내시경을 이용하였을 경우에는 이용하지 않았 을 때보다 더 깊은 곳에 위치한 농양까지도 배농시킬 수 있 었다. 다만 본 연구가 후향적 연구로서, 저자들이 농양의 깊이 가 깊을 경우, 시야 확보를 위해 나안보다는 내시경을 선호하 여 위와 같은 결과가 나올 수 있다. 부인두의 해부학적 하연인 설골 부위쪽 후두와 측인두 부위에도 내시경은 좋은 시야를 제공해 줄 수 있다. 측인두 점막 부종으로 해부학적 지표가 변형되고 수술 공간이 좁아진 경우에도, 내시경은 병변 부위 확대가 가능하여 공간과 깊이의 제한을 극복할 수 있다. 경 구강 절개배농은 측인두의 돌출(bulging)이나, 함입(indentation)과 같은 해부학적 기준점(landmark)이 중요한 지표가 된다. CT에서 확인한 농양 부위를 덮고 있는 측인두의 이러 한 해부학적 기준점들은 내시경으로 확인할 때 더 정확하게 
구별할 수 있어 바늘흡인의 정확도를 높일 수 있다. 내시경과 더불어 고주파수 기구인 Coblator를 이용하면, 점막 절제와 지혈이 가능하여, 시야 확보에 더욱 유리하다. 바늘흡인에만 의존하지 않고, 농양 부위를 덮고 있는 점막이나 점막하 조직 을 Coblator로 절제할 수 있어, 농양을 덮고 있는 부위를 얇게 하거나 절제하여, 농양 노출이 용이하다(Fig. 1). Coblator 기 구는 점막이나 점막하 조직은 비교적 용이하게 절제가 가능 하나, 근육은 쉽게 절제하지 않아, 근육 외측에 위치한 주요 혈관의 손상을 피할 수 있는 장점이 있다. 내시경을 이용하여 설근부와 설편도 절제 방식은 이미 수면 수술 분야에서 활발 히 이루어지고 있다. ${ }^{20)}$ 우리 연구에서도 위의 방식을 채용하 여 설골 주변까지도 접근이 가능하였다.

내시경을 사용한 그룹에서 사용하지 않은 그룹에 비해 수 술 중 혈액 손실이 유의하게 적을 것으로 기대하였지만, 그렇 지 않았다. 내시경을 통해 병소를 확대 관찰할 수 있어 지혈 에 뛰어났지만, 후향적 연구 방식의 한계와, 우리가 채택한 추 정 혈액 손실량은 수술 전후 혈색소를 이용하는 방식이어서 수술 전후 수액의 양 등에 영향을 많이 받는 단점이 있다. 또 한, 혈색소 측정은 환자의 염증 상태나 영양 상태에 따라 변 동성이 있을 수 있기 때문에 수술 중 혈액 손실을 충분히 반 영할 수 없다는 단점이 있다. 본 연구의 단점으로는 후향적 연구이며, 수술자가 동일하지 않다는 점, 비교대상군의 수가 적다는 점이다. 그러나, 나이, 성별, $\mathrm{CRP}$, 기관절개술이 시행 된 경우, 당뇨병의 과거력, 항응고제를 복용한 경우에서 차이 가 나지 않기 때문에, 두 그룹의 중등도는 상당히 비슷하다고 할 수 있다. 추후에 전향적 연구나, 다기관 연구 등을 통해서 극복해야 할 문제라 생각한다.

\section{Acknowledgments}

None.

\section{Author Contribution}

Conceptualization: Myoung Su Choi. Data curation: Myoung Su Choi. Formal analysis: Dong Sik Chang. Investigation: Jun Lee, So Young Choi. Methodology: Myoung Su Choi. Project administration: Dong Sik Chang. Resources: Dong Sik Chang. Software: Myoung Su Choi. Supervision: Dong Sik Chang. Validation: Myoung Su Choi. Visualization: Myoung Su Choi. Writing — original draft: Myoung Su Choi. Writing — review \& editing: Myoung Su Choi.

\section{ORCID}

Myoung Su Choi https://orcid.org/0000-0003-4553-7808

\section{REFERENCES}

1) Amar YG, Manoukian JJ. Intraoral drainage: Recommended as the initial approach for the treatment of parapharyngeal abscesses.
Otolaryngol Head Neck Surg 2004;130(6):676-80.

2) Gidley PW, Ghorayeb BY, Stiernberg CM. Contemporary management of deep neck space infections. Otolaryngol Head Neck Surg 1997;116(1):16-22.

3) Oh JH, Kim Y, Kim CH. Parapharyngeal abscess: Comprehensive management protocol. ORL J Otorhinolaryngol Relat Spec 2007; 69(1):37-42.

4) Page C, Biet A, Zaatar R, Strunski V. Parapharyngeal abscess: Diagnosis and treatment. Eur Arch Otorhinolaryngol 2008;265(6): 681-6.

5) Kim CH, Kim YG, Choung YH, Lee JW. A clinical study of parapharyngeal abscess. Korean J Otorhinolaryngol-Head Neck Surg 2003;46(9):769-74.

6) Koivunen P, Löppönen H. Internal carotid artery thrombosis and Horner's syndrome as complications of parapharyngeal abscess. Otolaryngol Head Neck Surg 1999;121(1):160-2.

7) Sethi DS, Stanley RE. Parapharyngeal abscesses. J Laryngol Otol 1991;105(12):1025-30.

8) Nadler SB, Hidalgo JH, Bloch T. Prediction of blood volume in normal human adults. Surgery 1962;51(2):224-32.

9) Klug TE, Fischer AS, Antonsen C, Rusan M, Eskildsen H, Ovesen T. Parapharyngeal abscess is frequently associated with concomitant peritonsillar abscess. Eur Arch Otorhinolaryngol 2014;271(6):1701-7.

10) Monobe H, Suzuki S, Nakashima M, Tojima H, Kaga K. Peritonsillar abscess with parapharyngeal and retropharyngeal involvement: Incidence and intraoral approach. Acta Otolaryngol Suppl 2007; (559):91-4.

11) Kawabata M, Umakoshi M, Makise T, Miyashita K, Harada M, Nagano $\mathrm{H}$, et al. Clinical classification of peritonsillar abscess based on $\mathrm{CT}$ and indications for immediate abscess tonsillectomy. Auris Nasus Larynx 2016;43(2);182-6.

12) Licameli GR, Grillone GA. Inferior pole peritonsillar abscess. Otolaryngol Head Neck Surg 1998;118(1):95-9.

13) Hah YM, Jung AR, Lee YC, Eun YG. Risk factors for transcervical incision and drainage of pediatric deep neck infections. J Pediatr Surg 2018;53(4):666-70.

14) Dabirmoghaddam P, Mohseni A, Navvabi Z, Sharifi A, Bastaninezhad S, Safaei A. Is ultrasonography-guided drainage a safe and effective alternative to incision and drainage for deep neck space abscesses? J Laryngol Otol 2017;131(3):259-63.

15) Yusa $H$, Yoshida $H$, Ueno E, Onizawa K, Yanagawa T. Ultrasoundguided surgical drainage of face and neck abscesses. Int J Oral Maxillofac Surg 2002;31(3):327-9.

16) Delides A, Manoli E, Papadopoulos M, Nikolopoulos T. Ultrasoundguided transoral drainage of a paediatric parapharyngeal abscess. J Laryngol Otol 2014;128(12):1120-2.

17) Sichel JY, Dano I, Hocwald E, Biron A, Eliashar R. Nonsurgical management of parapharyngeal space infections: A prospective study. Laryngoscope 2002;112(5):906-10.

18) McClay JE, Murray AD, Booth T. Intravenous antibiotic therapy for deep neck abscesses defined by computed tomography. Arch Otolaryngol Head Neck Surg 2003;129(11):1207-12.

19) Cable BB, Brenner P, Bauman NM, Mair EA. Image-guided surgical drainage of medial parapharyngeal abscesses in children: A novel adjuvant to a difficult approach. Ann Otol Rhinol Laryngol 2004; 113(2):115-20.

20) Wee JH, Tan K, Lee WH, Rhee CS, Kim JW. Evaluation of coblation lingual tonsil removal technique for obstructive sleep apnea in Asians: Preliminary results of surgical morbidity and prognosticators. Eur Arch Otorhinolaryngol 2015;272(9):2327-33 